\title{
The effect of academic motivation on students' English learning achievement in the eSchoolbag-based learning environment
}

\author{
Shan Li* (D) and Juan Zheng
}

* Correspondence:

shan.li2@mail.mcgill.ca

Faculty of Education, McGill

University, Montreal, QC, Canada

\begin{abstract}
The electronic schoolbag (eSchoolbag) provides instructors and students a smart learning environment as the log file data could be used to support learner modelling and learning analysis, making adaptive and personalized learning possible. Abundant of studies have documented the design and implementation of the eSchoolbag. However, the relationship between students' learning achievement and their motivational factors is still unclear when using eSchoolbag to learn English. Thus, this study examined the effect of students' academic motivation on their English learning achievement in the eSchoolbag-based learning environment. A total of 78 participants were involved in the study, and their English learning achievement were assessed six times during 1 year. Moreover, 63 students finished the academic motivation questionnaire, and they were clustered into two groups using K-means clustering algorithm. The two groups were labelled as the high and low motivation group respectively. The research found that the eSchoolbag-based learning environment had a significantly positive effect on students' learning achievement. Besides, students' academic motivation also had the ability to differentiate their learning achievement when using eSchoolbag to learn English. Furthermore, this research found that students' prior levels of learning achievement had no significant association with their academic motivation. There was also no significant association between student's gender and his/her academic motivation. In terms of components of academic motivation, students' attainment value of using eSchoolbag to learn English was correlated positively with their learning achievement.
\end{abstract}

Keywords: eSchoolbag, Academic motivation, Learning achievement, English learning

\section{Introduction}

The integration of tablet computers (TC) into classroom has gained great popularity all over the world (Blackwell, Lauricella, \& Wartella, 2016; Çuhadar, 2014; Tront, 2007). The deployment of TC into pedagogical practices could facilitate the process of knowledge acquisition and transmission, accelerate students' understanding towards certain problems, and enrich teachers' teaching strategies and methods, which makes the teaching and learning pretty promising (Wang \& Towey, 2012; Gu, Zhu, \& Guo,

(c) The Author(s). 2017 Open Access This article is distributed under the terms of the Creative Commons Attribution 4.0 International License (http://creativecommons.org/licenses/by/4.0/), which permits unrestricted use, distribution, and reproduction in any medium, provided you give appropriate credit to the original author(s) and the source, provide a link to the Creative Commons license, and indicate if changes were made. 
2013; Disterer \& Kleiner, 2013). Abundant of instructional applications, vary from electronical learning materials to context-based learning activities, have been developed to meet students' learning need. And the applications can be easily installed on TC, making learning pretty convenient (Bocconi, Kampylis, \& Punie, 2013; Cuban, 2006). For example, e-Textbooks can provide learners with rich learning resources on just one TC, reducing the need to carry heavy book bags for students. However, TC-based learning equates self-directed learning to some extent (Leinonen, Keune, Veermans, \& Toikkanen, 2014), since the teaching and learning process separates from each other when students learn on their personal tablet computers. Teachers are not effectively involved in students' learning.

Therefore, an integrated solution known as the eSchoolbag (electronic schoolbag) came to researchers' sights. In essence, the eSchoolbag is an intelligent teaching and learning platform for teachers and students (Ni et al., 2015). The eSchoolbag promises students' learning on TC under the guidance of their teachers. In the classroom context, every student holds a eSchoolbag device which allows them to participate in various activities, while teachers use the eSchoolbag with administrative functions. Thus, the teachers are able to control students' learning processes by allocating learning resources, organizing group discussions, monitoring students' screens and assigning tasks. Lots of studies have examined students' acceptance of eSchoolbag (Lai \& Lai, 2013) and the design of eSchoolbag systems (Chang \& Sheu, 2002; Kong, 2015). However, few research had focused on the effect of students' academic motivation of using eSchoolbag to learn English on their learning achievement, and how students' academic motivation could affect their learning achievement. Thus, this study aims to examine the effects of both the eSchoolbag-based learning environment and students' academic motivation on their learning achievement. This study also tries to reveal the rationale regarding how students' academic motivation affect their learning achievement if the effect exists.

\section{Theoretical framework}

\section{The rise and development of one-to-one laptop initiative}

Research that pertains to the integration of information and communication technology (ICT) into classrooms has seen the widespread, dramatic use of technologies in scaffolding educational innovations, including but not limited to the teaching machines, intelligent tutoring systems, online communities, individualized learning space, virtual reality and wearable devices (Lajoie \& Azevedo, 2005; Bocconi, Kampylis, \& Punie, 2013). However, computers and technologies often play a subsidiary role in facilitating teaching and learning in nowadays schools rather than an indispensable function that deeply incorporated into the daily instructional practices (Bebell, Russell, \& O'Dwyer, 2004; Ling Koh, Chai, \& Tay, 2014). Consequently, administrators and teachers generally report making use of computers in classrooms for only a small amount of time each day (Bebell \& Kay, 2010). Many researchers pointed out that the disjunction between the extensive increase in the presence of kinds of technologies in school environments and the relatively inert amount of computer use results partially because the low student-to-computer ratios (Cuban, 2006; Bull, Bull, Garofalo, \& Harris, 2002; Windschitl \& Sahl, 2002). Under this circumstance, Norris, Soloway and Sullivan (2002) 
raised the concept of One-to-One (also known as 1:1) which means that 1:1 student to computer access in schools, for the purpose of education change by leveraging the lowcost, palm-size computers to each student. And increased international governments and researchers have focused their attention on the adoption of One-to-One computing through programs such as 'Up-scaling creative classrooms in Europe' (Bocconi et al., 2013), 'One Laptop Per Child' (Kraemer, Dedrick, \& Sharma, 2009), and 'Bring You Own Device' (Disterer \& Kleiner, 2013).

The One-to-One programs share two fundamental characteristics: 1) each individual in the classroom is equipped with a digital device and internet access; 2) the digital devices are served as instructional purposes (e.g. class managements, cognitive and metacognitive tools, virtual agents) (Penuel, 2006). However, it's important to notice that the "One-to-One computing" provides no substantial guidance to actual educational practices by definition (Bebell \& Dwyer, 2010). Though all One-to-One programs involve 1:1 technology access, "each 1:1 setting had its own unique set of expectations, funding mechanisms, and individual implementation models including variation in hardware, software, networking, teacher training and professional development, as well as program support" (Bebell \& Dwyer, 2010, p. 6). The eSchoolbag, as one type of One-toOne computing environments, gained great popularity in China due to its technologyrich characteristics and curriculum-based designs, reflected in large numbers of eSchoolbag-based programs that leaded by local governments, a variety of proclamations that eSchoolbag systems offer unprecedented opportunities in national educational reform (Gu, Zhu, \& Guo, 2013; Gu \& Zhang, 2014).

\section{The eSchoolbag as an enhanced one-to-one environment to optimizing instruction}

According to Chabert (2006), an eSchoolbag system is a virtual learning environment that helps learners to access resources and services through a single interface without limitation of time and space. When it comes to the pedagogical practices, the eSchoolbag is often regarded as an intelligent teaching and learning system that installed on a Table PC, equipping with electronic textbooks, learning resources, projection display services and teaching control functions (Xie et al., 2015). Features as touch screen input, handwriting-recognition, and other applications designed to assist particular subjects could also be integrated into the eSchoolbag systems based on their educational purposes and needs (Wang \& Towey, 2012).

The eSchoolbag has great potential in tailoring instruction and maximizing students' learning performance, as it compromises the ideas of student-centered, project-based and problem-based learning within technology-rich environments (Grubelnik, 2016). According to Xie and his colleagues (2015), the eSchoolbag is particular effective in supporting problem-oriented instructions, since it immerses students into authentic problem-solving situations, and it provides targeted metacognitive tools to help students manage their problem-analysis processes. Besides, the navigational data and learning trajectories recorded by the eSchoolbag system have great implications for adaptive instructions and real-time scaffoldings. The log file data could be analyzed for: 1) interpreting learner's behaviors based on domain-specific models; 2) inferring learner's requirements, preferences and learner states (e.g. cognitive workload, performance); and 3) providing instructional assistances upon available resources by computer 
agents or teachers (e.g. adjusting the complexity of task scenarios, altering the type of scaffoldings) (Paramythis \& Loidl-Reisinger, 2004; Sottilare, 2014; Wu et al., 2014). For example, the physical level of adaptions in system's interface, such as the changing of content layouts, sequences and formats, to accommodate learner attributes, preferences or needs (Cabukovski \& Tusevski, 2015); and the adaptions in presented contents through reconstructing, discovering and assembling the most 'fit' learning resources to match learner's requirements and characteristics (Paramythis \& Loidl-Reisinger, 2004; Brusilovsky, 2001). By doing this, the eSchoolbag promises a personized but highlysupportive learning environment, though the eSchoolbag programs come in different forms and can be employed across various disciplines.

What's more, plenty of empirical findings from the eSchoolbag research have corroborated its effectiveness in optimizing teaching and learning practices. Research from $\mathrm{Ni}$ et al. (2015) revealed that the eSchoolbag stimulated students' interests in mathematics learning, as well as enhanced their ability of cooperation, resulting in a significant improvement of learning outcomes. This is in accordance with the research of Xie et al. (2015), which claimed that the eSchoolbag can effectively improve students' problemsolving capabilities in handling with mathematical issues. The eSchoolbag was also effective in developing students' English oral communication ability in junior middle schools, as it provided learners a variety of real simulation environments and cognitive scaffoldings (Xie et al., 2016). According to Doukas et al. (2009), the eSchoolbag provides learner the opportunities to construct new knowledge and personal experiences from a situated, activity-intensive orientation, making the eSchoolbag-based classroom an ideal place to develop students' twenty-first Century skills.

In essence, the eSchoolbag encourages learners to develop flexible understanding from multiple perspectives by inducing them to link learning contents to their everyday experiences, with the instructor as a facilitator rather than a focal point (Xie et al,, 2015). However, on the other hand, it means that the eSchoolbag requires learners to allocate more cognitive and emotional effort than traditional learning environments. In fact, some researchers have pointed out that some students had low motivations in using eSchoolbag to assist their learning, since the eSchoolbag impeded them in concentrating their attentions (Dong, 2011; Wang, 2012).

\section{The interplay of academic motivation, learning achievement and the eSchoolbag}

Academic motivation can be defined as a form of cognitive and emotional arousal that influence a learner's academic achievement (Vallerand et al., 1992). According to Hakan and Münire (2014), academic motivation is an internal state that activates, directs and maintains learning-related behaviors. Two main types of motivation, extrinsic and intrinsic motivation, lie as groundwork underpropping a large number of theories of motivation such as expectancy-value theory (Wigfield, Tonks, \& Klauda, 2009; Wigfield \& Eccles, 2000), goal orientation models (Anderman, Austin, \& Johnson, 2002), attribution theory (Kelley \& Michela, 1980; Weiner, 2008), as well as self-determination theory (Deci, Vallerand, Pelletier, \& Ryan, 1991), self-efficacy theory (Zimmerman, 2000). These theories provide researchers and instructors great understanding of academic motivation in teaching and learning setting, and valuable information regarding how students adjust to various learning environments. First, a learner's academic motivation 
is the result of interactions between classroom factors and the student's particular characteristics (Wigfield \& Eccles, 2000). Thus, classroom goal structures, teacher reactions to student performance, and individual differences should be carefully designed or examined in the educational setting (Gredler, 2001). Second, the student is an active processor and interpreter of the classroom setting, so student's academic motivation can be enhanced by engaging students in meaningful learning activities (Gredler, 2001). Third, students can reflect on and report their perceptions of academic motivation to others (Murphy \& Alexander, 2000), making it possible to collect students' motives and needs in forms of surveys.

The question regarding to whether academic motivation predicts student learning achievement is important in educational practices. Although students' academic motivation can change with environmental and interpersonal factors, researchers had made consensus that educators, parents and school administrators should create conditions for students to stimulate their motivation, which would have the potential to improve their learning performance in consequence (Guay, Ratelle, Roy \& Litalien, 2010). However, on one hand, there is no liner correlation between students' academic motivation and their learning performance, owing to the complexity of learning process (Fortier, Vallerand, \& Guay, 1995). On the other hand, it's important to notice that students' academic motivation vary in terms of gender, domain and grade (Hakan \& Münire, 2014). And one shared assumption of motivation models is that motivation is subject-specific, which means students' academic motivation may differ for English, math, science and other courses (Gredler, 2001).

A broad range of research had demonstrated the positive influence of the eSchoolbag on students' motivations, which always lead to improvement in learning outcomes (Chabert et al., 2006; Wang \& Towey, 2012; Xie et al., 2015). The rationales partly lie in the highly interactive environments provided by the eSchoolbag which satisfy the characteristics of students in current schools, also known as 'digital natives' who consider technology as their basic lifestyle (Gu et al., 2013). Another reason as revealed by Gu and Zhang (2014), parents and students have much expectations in classroom innovations and the eSchoolbag programs with the rising of 'One-to-One computing' around the world. Thus, when taking eSchoolbag into classroom practice, students tend to have high motivation to use it. However, on one hand, few research has focused on how students' perceptions towards the eSchoolbag affect their learning achievements. Each student comes to the classroom with their own personalities, expectation and values, it's crucial to examine how students' motivations and its internal elements (e.g. attainment value, intrinsic value, utility value and cognitive cost) interplay with their learning performance when using eSchoolbag to assist classroom teaching and learning. On the other hand, with regard to the variation of students' learning outcomes in the eSchoolbag-based environments, a longitudinal analysis rather than a shortterm study has the potential in making conclusions more convincing, considering the fact that the change of learning performance needs a lasting progress. Thus, this study was designed to examine the effect of students' academic motivations on their English learning achievement in the eSchoolbag-based learning environment through a longitudinal observation and analysis. The mechanism of how students' motivational elements interplay with their learning outcomes was also carefully examined. Concretely, two research questions were formulated.

1. What effect did the eSchoolbag-based learning environment have on students' English learning achievement? 
2. Did students' academic motivation have a significant effect on their learning achievement when using eSchoolbag to learn English? If true, what's the rationale behind it?

\section{Methods}

\section{Participants}

A total of 78 students from the seventh grade of one middle school in Shenzhen were involved in this study. All students were taught by the same English teacher who has extensive teaching experience.

\section{Materials}

The academic motivation questionnaire used in this study was adapted from Pintrich and De Groot (1990), in accordance with Wigfield and Eccles's (2000) motivational model. The questionnaire consists four parts: attainment value, intrinsic value, utility value and cost, as shown in Table 1. All items of the questionnaire were presented using a 5-point Likert scale with 1 as 'strongly disagree' and 5 stands for 'strong agree'. The scale reliability was analyzed to check the internal consistency of the questionnaire. Specifically, the Cronbach's coefficient of the whole scale was 0.89. The Cronbach's coefficient of attainment value, intrinsic value, utility value, and cost were $0.80,0.84,0.66$ and 0.72 respectively.

The eSchoolbag software applied in this research is shown in the Fig. 1. The eSchoolbag provides students a technology-rich learning environment with kinds of learning resources, scaffoldings, cognitive and metacognitive tools. And it also gives students the opportunity to record and track their learning trajectories, making learning analysis and reflective learning possible. Besides, as an integrated learning environment, the eSchoolbag can meet students' need of ubiquitous learning without limitation of time and space, their need of collaborative learning both in and out the class.

\section{Procedures}

This study aims to examine the effects of both the eSchoolbag-based learning environment and students' academic motivation on their learning achievement. In order to examine whether the eSchoolbag-based learning environment made a significant difference on students' learning achievement or not, a longitudinal experiment was conducted with repeated-measures design. Specially, students' learning achievement were assessed by their scores in English exams.

Table 1 Motivational Model of Using eSchoolbag to Learn English

\begin{tabular}{|c|c|}
\hline Component & Definition \\
\hline $\begin{array}{l}\text { Attainment } \\
\text { value }\end{array}$ & The importance of using eSchoolbag to learn English subject \\
\hline Intrinsic value & $\begin{array}{l}\text { The enjoyment for the students of using eSchoolbag to learn English or the students' interest } \\
\text { of using eSchoolbag to learn English }\end{array}$ \\
\hline Utility value & The usefulness of taking eSchoolbag as a mean to learn English \\
\hline Cost & The extent of students' cognitive load when using eSchoolbag to learn English \\
\hline
\end{tabular}

Revised from Wigfield \& Eccles, 2000 


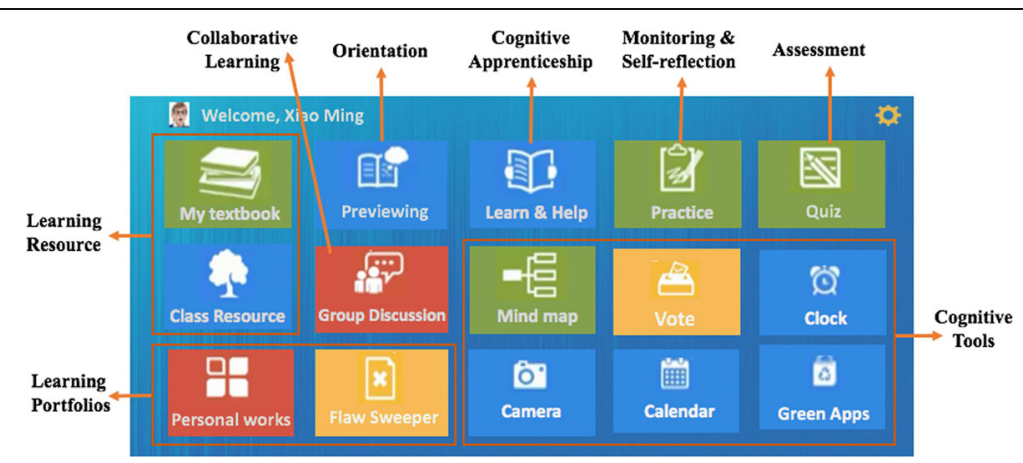

Fig. 1 The interface and features of the eSchoolbag. When teachers release learning resource on the server side, students can have a view of the resource in My Textbook and Class Resource. Before the class, they can orientate and plan their learning by using the Previewing function on the e-Schoolbag. In the Learn \& Help part, the software provides students a cognitive-apprenticeship environment to get immediate help from teachers. There is also an online Group Discussion where students can communicate with each other or work collaboratively to solve complex subject topics. In order to control their paces of learning, and adjust their learning based on their performance, students are provided with Practice and Quiz to monitor and assess their learning at the time they want. They can reserve the mistakes or unfamiliar knowledge into Flaw Sweeper for them to review regularly. The e-Schoolbag also includes several cognitive tools that promote cognitive monitoring and control strategies critical to classroom learning, such as mind map, vote, clock, calendar and camera. It's important to notice that the e-Schoolbag is open to green apps too. Based on the requirement of teachers and students, the apps that promote effective teaching and learning will be allowed to install on the e-Schoolbag

As shown in Fig. 2, student's prior level of English learning achievement was measured as the average score of three pretests. A total of 78 students finished these pretests with an interval of one month. Then an eSchoolbag training was provided to make sure that every student had a primary understanding of how the eSchoolbag looks like and how it could affect English learning. The same teacher conducted the training in the classroom environment for students. After the training, students were required to finish the questionnaire regarding to their academic motivation of using the eSchoolbag to assist learning. Amongst the 78 students, 63 students ( 36 boys and 27 girls) had finished the questionnaire. The eSchoolbag were deployed in the English courses afterwards. The pedagogical practice of English classes lasted for one year in the eSchoolbag-based learning environment with no students dropped out. Similar with

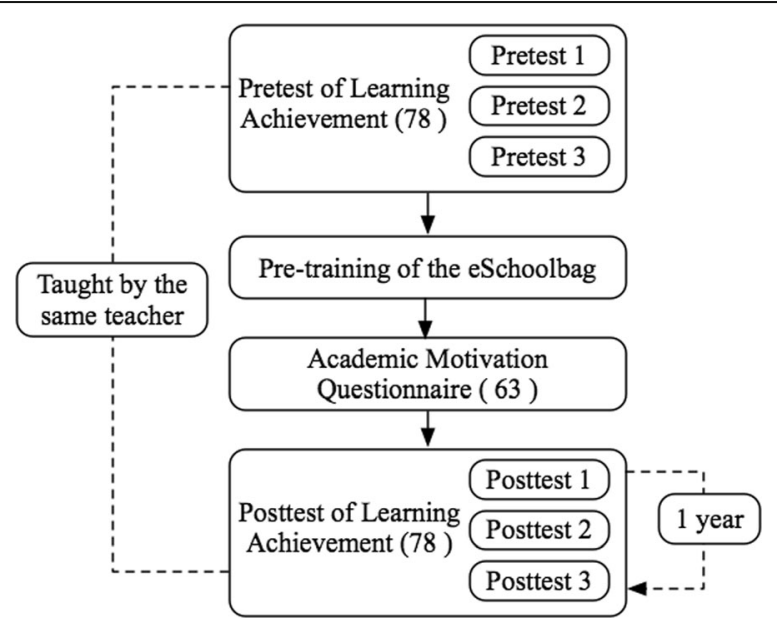

Fig. 2 The procedure of the experiment 
the design of the pretests, students' learning achievement were tested for three times in the last three months of the experiments with the test interval of one month as well.

In order to exclude random factors from the experiment, several measures were conducted to minimize unintentional and external influences. First, student's prior level of English learning achievement was measured as the average score of three pretests, while the interval of these pretests was 1 month. In the pretests, students had no idea about the eSchoolbag, and the eSchoolbag haven't been used in the classroom practice. In doing so, a relatively correct estimate of students' prior English-learning levels were acquired. Second, this study was designed as a longitudinal research that involves repeated observations of students' learning outcomes to ensure that the differences observed were more accurate. Third, similar with the design of the pretests, students' learning achievement were tested for three times with an interval of 1 month after using eSchoolbag for 9 months. Last, it's important to mention that the English exams taken in the pretests and posttests were designed by school English-teaching teams as standardized tests, whose validity can be verified to some extent.

In order to clarify the effect of academic motivation on students' learning performance when using eSchoolbag to assist English learning in classroom environment, the participants were divided into two groups according to their academic motivation. Concretely, the two groups were created using the K-means clustering algorithm, and named as the high and low group respectively. The students in the high group had relatively higher academic motivation than students in the low group. The clustering centroids of students' attainment value, intrinsic value, utility value and cost for both the high group and low group were optimum as shown in Table 2. Furthermore, there was 36 students in the high group, and 27 in the low group.

However, for the sake of minimizing exterior influences on students, students had no idea about the grouping.

\section{Results}

Research question 1: What effect did the eSchoolbag-based learning environment have on students' English learning achievement?

A paired T-test was performed to identify, for the same group of students, if there was a significant difference on the learning achievement between the eSchoolbag-free learning environment and the eSchoolbag-based learning environment. In order to minimize the influence of random factors on students' learning achievement, three tests were conducted both in the pretest and posttest. The student's learning achievement were calculated as the mean of the three tests.

Table 2 Grouping based on participants' academic motivation

\begin{tabular}{llllll}
\hline Group & Number & Centroid & & \\
\cline { 3 - 6 } & & Attainment value & Intrinsic Value & Utility value & Cost \\
\hline High & 36 & 4.7 & 4.5 & 4.1 & 1.5 \\
Low & 27 & 3.6 & 3.1 & 3.3 & 2.5 \\
\hline
\end{tabular}


The results in Table 3 indicate that there was a significant difference between the learning achievement when participants took the eSchoolbag to learn English compared to the English learning without the eSchoolbag, $t(77)=3.03, p<0.01$. On average, participants performed better when using the eSchoolbag to assist their learning $(M=86.49, S D=10.32)$ as opposed to the English learning without the eSchoolbag $(M=84.48, S D=14.07)$.

Research question 2: Did students' academic motivation have a significant effect on their learning achievement when using eSchoolbag to learn English? If true, what's the rationale behind it?

As mentioned above, participants were divided into two groups based on their academic motivation by the K-means clustering algorithm. The two groups were defined as the high and low group respectively, as the students in the high group had relatively higher academic motivation than students in the low group. In detail, there was 36 students in the high group, and 27 in the low group. An independent T-test was conducted to find that there was no statistically significant difference on the learning achievement between these two groups in the pretest, when the participants had not use eSchoolbag to assist their English learning. However, in the posttest of students' learning achievement, the independent T-test revealed that there was a statistically significant difference in the scores between students with high academic motivation $(M=90.76, S D=5.75)$ and those with low academic motivation $(M=87.25, S D=5.87)$ in the eSchoolbag-based learning environment, $t(61)=2.37, p<0.05$, $d=0.61$, as shown in Table 4.

Students' academic motivation had a positive effect on their learning achievement when using eSchoolbag to learn English. However, the rationale behind this fact could be more important to understand effective teaching and learning in the future. Thus, the research further examined why some students had relevantly higher academic motivation than others, which lead them to better learning performance in consequence. Specifically, students' gender, and their prior levels of learning performance were taken into consideration.

In order to examine whether student's prior level of learning achievement has significantly different effects upon his/her academic motivation or not, students were divided into two groups using the K-means clustering algorithm as well. Then a Chi-Square $\left(x^{2}\right)$ test was performed. The test result indicated that there was no statistically significant association between students' prior levels of learning achievement and their academic motivation, $X^{2}(1, N=63)=3.64, p=0.056$. However, it's important to notice that students with high prior level of learning achievement $(M=89.73, S D=8.44)$ were in the high motivation group, while those with low prior level of learning achievement $(M=86.29, S D=8.47)$ had relatively low academic motivation, though no significant

Table 3 Results of Paired t-test and Descriptive Statistics for Learning Achievement

\begin{tabular}{|c|c|c|c|c|c|c|c|}
\hline \multirow[b]{2}{*}{ Learning Achievement } & \multicolumn{2}{|c|}{ Pretest } & \multicolumn{2}{|c|}{ Posttest } & \multirow[b]{2}{*}{$t$} & \multirow[b]{2}{*}{$d f$} & \multirow[b]{2}{*}{ Sig. (2-tailed) } \\
\hline & $\bar{M}$ & SD & $\bar{M}$ & $S D$ & & & \\
\hline & 84.48 & 14.07 & 86.49 & 10.32 & 3.03 & 77 & $0.003^{* *}$ \\
\hline
\end{tabular}

** $p<.01$ 
Table 4 Comparison of Learning achievement between high and low group

\begin{tabular}{lllllc}
\hline Learning Achievement & $M$ & $S D$ & $t$ & $d f$ & Sig. (2-tailed) \\
\hline Pretest & & & 1.60 & 61 & 0.116 \\
High Group & 89.73 & 8.44 & & & \\
Low Group & 86.29 & 8.47 & & 61 & $0.021^{*}$ \\
Posttest & & & 2.37 & & \\
High Group & 90.76 & 5.75 & & & \\
Low Group & 87.25 & 5.87 & & & \\
${ }^{*} p<.05$ & & & & &
\end{tabular}

difference was found with regard to their prior learning achievement as shown in Table 4. Another Chi-Square $\left(x^{2}\right)$ test was conducted to find if students' gender has significantly different effects on his/her academic motivation. The result shows that there was no association between students' gender and their academic motivation.

To explore possible interactions between learning achievement and different dimensions of academic motivation, a Pearson correlation coefficient test was also conducted. The results of the test are presented in Table 5 .

A close examination of Table 5 shows that learning achievement, correlated positively with student's attainment value of using eSchoolbag to learn English $(r(63)=.263, p<.05)$. Other correlation coefficients between learning achievement and motivational components as intrinsic value, utility value and cost, did not achieve any statistical significance.

\section{Discussion}

This study examined the effect of eSchoolbag-based learning environment on students' English learning achievement. The research found that the eSchoolbag-based learning environment had a significantly positive effect on students' learning achievement. When using eSchoolbag to assist students' English-learning, they could perform better as reflected in the English tests. The results were in accordance with the researches of Guay (2010) and Grubelnik (2016) who claimed that eSchoolbag-based learning environment is generally considered beneficial for both self-regulated learning and collaborative learning. The reasons lied in the immersing, simulating and practicing learning environment, as well as the interactive and targeted learning activities that provided by the eSchoolbag to scaffold students' learning. Based on the log file data collected by the eSchoolbag, students' learning trajectory and cognitive characteristics could be analyzed, providing instructors significant implications to adjust their pedagogical designs and assessment approaches (Wu et al., 2014). The research also found that students'

Table $\mathbf{5}$ Relationship between learning achievement and academic motivation

\begin{tabular}{llllll}
\hline & 1 & 2 & 3 & 4 & 5 \\
\hline 1. Attainment value & 1 & & & & \\
2. Intrinsic value & $.761^{* *}$ & 1 & & & \\
3. Utility value & $.504^{* *}$ & $.409^{* *}$ & 1 & 1 & \\
4. Cost & $-.421^{* *}$ & $-.527^{* *}$ & -.202 & -.149 & 1 \\
5. Learning achievement & $.263^{*}$ & .114 & -.018 &
\end{tabular}


cognitive load had no significant association with their learning achievement when using eSchoolbag to learn English. The result undermined the proclamations of Wang (2012) and Dong (2011) that the eSchoolbag-based learning may burden students' cognitive load, and worsen students' learning performance in consequence.

The findings that students' academic motivation is a determinant of their learning achievement, are keeping in with the findings of Linnenbrink \& Pintrich (2002) and Green, Nelson, Martin, \& Marsh (2006). Students' academic motivation had a positive effect on their learning achievement when using eSchoolbag to learn English. Specially, the English learning achievement of students with high academic motivation were significantly higher than the learning achievement of those with low academic motivation. Thus, the proposition that instructors should create environments to stimulate and enhance students' academic motivation need to be seriously considered when deploying eSchoolbag in classrooms.

However, in contrast with the research of Hakan \& Münire (2014), the results in this study showed that students' gender had no significantly different effects on their academic motivation. The research further examined the relationship between students' prior levels of learning achievement and their academic motivation towards the use of the eSchoolbag in assisting English learning. No significant association was observed as well. Although there was no statistically significant difference on students' prior learning achievement between the high and low motivation groups, the mean score of students' learning achievement in high motivation group was higher than that in the low motivation groups. This can be explained, to some extent, that students' prior levels of learning achievement had a positive effect on students' self-efficacy (Bandura, 1993), while self-efficacy is a significant predicator of students' academic motivation (Schunk, 1991).

An examination of relationships between students' learning achievement and motivational components revealed that learning achievement correlated positively with student's attainment value of using eSchoolbag to learn English. However, students' intrinsic value and utility value were not significantly associated with their learning achievement. It is mature to assume that students valued the importance of using eSchoolbag to learn English more than the factors of enjoyment and usefulness. Consistent with the findings of Sheldon and Elliot (1998), students may not truly "motivated" though their academic motivation are self-generated. It is possible that the environmental factors, such as teachers' attitude, family support and social contexts, could interact with their academic motivation, making them convinced that using eSchoolbag in English learning was important. Thus, on one hand, as suggested by Guay, Ratelle, Roy and Litalien (2010), educators, parents and school administrators should create conditions for students to stimulate their motivation. On the other hand, how to stimulate and enhance students' intrinsic motivation should be taken into consideration.

\section{Conclusion}

With the development of cloud computing and wireless technology, students' physical schoolbags would be replaced by hand-held computers (Chan, Hue, Chou, \& Tzeng, 2001). As a smart learning environment, the eSchoolbag has gained great popularity during the last decade, as it promises students adaptive, personalized learning support and feedback. Since many instructors, parents, and administers had cast doubt on the 
effectiveness of the eSchoolbag, this research would be helpful to clear the air. It's not unsafe to say that using eSchoolbag in English learning could improve students' learning performance. And when it comes to student' learning achievement, their academic motivation could be an important enabler and predictor. Students with high academic motivation tended to gain good performance while there was no gender difference. The research also found that students' prior levels of learning achievement had no significant association with their academic motivation, suggesting that students with diverse English-learning levels can be motivated to use the eSchoolbag, thus leading to an improvement in their learning achievement in consequence. In terms of components of student's academic motivation, student's attainment value of using eSchoolbag to learn English was correlated positively with their learning achievement. These findings could inform the effective implementation of the eSchoolbag in classrooms.

Acknowledgements

This research was supported by Long-gang education bureau of Shenzhen (2015391).

\section{Authors' contributions}

Both authors read and approved the final manuscript.

\section{Ethics approval and consent to participate}

The data can be obtained on request in electronic copy by email. The research was conducted in accordance with the journal's ethical guidelines. All the participation (teacher and students) were voluntary. The authors declare that the work described was original research that has not been published previously, and not under considerations for publication elsewhere, in whole or in part.

\section{Competing interests}

The authors declare that they have no competing interests.

\section{Publisher's Note}

Springer Nature remains neutral with regard to jurisdictional claims in published maps and institutional affiliations.

Received: 21 March 2017 Accepted: 11 August 2017

Published online: 25 August 2017

\section{References}

Anderman, E. M., Austin, C. C., \& Johnson, D. M. (2002). The development of goal orientation. In Development of achievement motivation. (pp. 197-220). https://doi.org/10.1016/B978-012750053-9/50010-3

Bandura, A. (1993). Perceived Self-Efficacy in Cognitive Development and Functioning. Educational Psychologist. https:// doi.org/10.1207/s15326985ep2802_3

D. Bebell, L.M.O. Dwyer. (2010) Educational outcomes and research from 1:1 computing settings. Computing 9(1), 6$14 \mathrm{http}: / /$ ejournals.bc.edu/

D. Bebell, R. Kay. (2010) One to one computing: A summary of the quantitative results from the Berkshire wireless learning initiative. J Technol Learn Assessment 9(2), 60 https://doi.org/10.1556/ComEc.10.2009.1.10

D. Bebell, M. Russell, L. O'Dwyer. (2004) Measuring teachers' technology uses. J. Res. Technol. Educ. 37(1), 45-63 https:// doi.org/10.1080/15391523.2004.10782425

C.K. Blackwell, A.R. Lauricella, E. Wartella, The influence of TPACK contextual factors on early childhood educators' tablet computer use. Comput Educ 98, 57-69 (2016) https://doi.org/10.1016/j.compedu.2016.02.010

S. Bocconi, P. Kampylis, Y. Punie, Framing ICT-enabled innovation for learning: The case of one-to-one learning initiatives in Europe. Eur. J. Educ. 48(1), 113-130 (2013) https://doi.org/10.1111/ejed.12021

P. Brusilovsky, Adaptive hypermedia. User Model. User-Adap. Inter. 11, 87-110 (2001) https://doi.org/10.1023/A: 1011143116306

G. Bull, G. Bull, J. Garofalo, J. Harris, Grand challenges: Preparing for the technological tipping point. Learn Leading Technol 29(8), 6-12 (2002)

Cabukovski, V., \& Tusevski, V. (2015). An additional content development methodology in an adaptive agent based elearning environment. In Proceedings of the International Conference on e-Learning, ICEL (Vol. 2015-Janua, pp. 58-65)

G. Chabert, J.C. Marty, B. Caron, T. Carron, L. Vignollet, C. Ferraris, The electronic schoolbag, a CSCW workspace: Presentation and evaluation. Al Soc 20(3), 403-419 (2006) https://doi.org/10.1007/s00146-005-0026-1

T.-W. Chan, C.-W. Hue, C.-Y. Chou, O.J. Tzeng, Four spaces of network learning models. Comput. Educ. 37(2), 141-161 (2001) https://doi.org/10.1016/S0360-1315(01)00044-6

Chang, C. Y., \& Sheu, J. P. (2002). Design and implementation of ad hoc classroom and eSchoolbag systems for ubiquitous learning. In Proceedings - IEEE International Workshop on Wireless and Mobile Technologies in Education, WMTE 2002 (pp. 8-14). https://doi.org/10.1109/WMTE.2002.1039215

L. Cuban, The laptop revolution has no clothes. Educ Week 26(8), 29 (2006) 
C. Çuhadar, Information technologies pre-service teachers' acceptance of tablet PCs as an innovative learning tool. Kuram ve Uygulamada Egitim Bilimleri 14(2), 741-753 (2014)

E. Deci, R. Vallerand, L. Pelletier, R. Ryan, Motivation and education: The self-determination perspective. Educ. Psychol. 26(3), 325-346 (1991) https://doi.org/10.1207/s15326985ep2603\&4_6

G. Disterer, C. Kleiner, BYOD bring your own device. Procedia Technol 9, 43-53 (2013) https://doi.org/10.1016/j.protcy. 2013.12.005

Dong, C. (2011). E-schoolbag is Too Early to Replace the Paperback Textbooks. Shanghai Morning Post. Retrieved from http://zt.jfdaily.com/xwzt/life/2011/szto_69781/

C.I. Doukas, Y. Kotsanis, V. Economu, K. Riviou, in IADIS International Conference on Cognition and Exploratory Learning in Digital age, CELDA 2009. From the classroom of the future to the school of the future - a greek case study (2009), pp. $526-528$

Fortier, M. S., Vallerand, R. J., \& Guay, F. (1995). Academic Motivation and School Performance: Toward a Structural Model. Contemporary Educational Psychology. https://doi.org/10.1006/ceps.1995.1017

Gredler, M. E. (2001). Learning and instruction: Theory into practice. Upper Saddle River, N.J: Pearson/Merrill Prentice Hall.

J. Green, G. Nelson, A.J. Martin, H. (2006) Marsh, The causal ordering of self-concept and academic motivation and its effect on academic achievement. Int. Educ. J. 7(4), 534-546 http://handle.uws.edu.au:8081/1959.7/34916

V. Grubelnik, L. Grubelnik, in 2016 39th International Convention on Information and Communication Technology, Electronics and Microelectronics, MIPRO 2016 - Proceedings. Teaching physics in primary schools with tablet computers: Key advantages (2016), pp. 847-851 https://doi.org/10.1109/MIPRO.2016.7522257

X. Gu, R. Zhang, Innovative application of E-textbook: Experiences from international projects. Modern Distance Educ Res 1, 55-61 (2014)

X. Gu, Y. Zhu, X. Guo, Meeting the "digital natives": Understanding the acceptance of technology in classrooms. Educ Technol Soc 16(1), 392-402 (2013)

F. Guay, C.F. Ratelle, A. Roy, D. Litalien, Academic self-concept, autonomous academic motivation, and academic achievement: Mediating and additive effects. Learn. Individ. Differ. 20(6), 644-653 (2010) https://doi.org/10.1016/j. lindif.2010.08.001

K. Hakan, E. Münire, Academic motivation: Gender, domain and grade differences. Procedia - Social Behav Sci 143, 708-715 (2014) https://doi.org/10.1016/j.sbspro.2014.07.469

H.H. Kelley, J.L. Michela, Attribution theory and research. Annu. Rev. Psychol. 31, 457-501 (1980) https://doi.org/10.1146/ annurev.ps.31.020180.002325

X.M. Kong, Design of a personalised learning evaluation model of an e-schoolbag, based on big data. World Trans Eng Technol Educ 13(4), 497-501 (2015)

K.L. Kraemer, J. Dedrick, P. Sharma, One laptop per child. Commun. ACM 52(6), 66 (2009) https://doi.org/10.1145/ 1516046.1516063

Lai, I. K. W., \& Lai, D. C. F. (2013). Student acceptance of electronic schoolbag systems: An empirical study in China. In Lecture Notes in Computer Science (including subseries Lecture Notes in Artificial Intelligence and Lecture Notes in Bioinformatics) (Vol. 8038 LNCS, pp. 334-344). https://doi.org/10.1007/978-3-642-39750-9_31

Lajoie, S. P., \& Azevedo, R. (2005). Teaching and learning in technology-rich environments. In P. H. Winne (Ed.), Handbook of Educational Psychology (pp. 803-821). Psychology Press

Leinonen, T., Keune, A., Veermans, M., \& Toikkanen, T. (2014). Mobile apps for reflection in learning: A design research in K-12 education. British Journal of Educational Technology, 47(1), n/a-n/a. https://doi.org/10.1111/ bjet.12224

J.H. Ling Koh, C.S. Chai, L.Y. Tay, TPACK-in-action: Unpacking the contextual influences of teachers' construction of technological pedagogical content knowledge (TPACK). Comput Educ 78, 20-29 (2014) https://doi.org/10.1016/j. compedu.2014.04.022

E. Linnenbrink, P. Pintrich, Motivation as an enabler for academic success. Sch. Psychol. Rev. 31(3), 313-327 (2002) https://doi.org/10.1177/017084068800900203

P.K. Murphy, P.A. Alexander, A motivated exploration of motivation terminology. Contemp. Educ. Psychol. 25, 3-53 (2000) https://doi.org/10.1006/ceps.1999.1019

Ni, M., Kwok, L. F., Zhen, L., Xie, Y., Long, H., Zheng, X., \& Li, W. (2015). A study of an e-schoolbag supporting flipped classroom model for junior mathematics review class. In Lecture Notes in Computer Science (including subseries Lecture Notes in Artificial Intelligence and Lecture Notes in Bioinformatics) (Vol. 9167, pp. 243-254). https://doi.org/ 10.1007/978-3-319-20621-9_20

C. Norris, E. Soloway, T. Sullivan, Examining 25 years of technology in U.S. education. Commun. ACM 45(8), 15-18 (2002) https://doi.org/10.1145/545151.545166

A. Paramythis, S. Loidl-Reisinger, Adaptive learning environments and e-learning standards. Electron J Elearning 2(1), 181-194 (2004)

W.R. Penuel, Implementation and effects of one-to-one computing initiatives. J. Res. Technol. Educ. 38(3), 329-348 (2006) https://doi.org/10.1080/15391523.2006.10782463

P.R. Pintrich, E.V. De Groot, Motivational and self-regulated learning components of classroom academic performance. J. Educ. Psychol. 82(1), 33-40 (1990) https://doi.org/10.1037/0022-0663.82.1.33

D. Schunk, Self-efficacy and academic motivation. Educ. Psychol. 26(3), 207-231 (1991) https://doi.org/10.1207/ s15326985ep2603\&4_2

K.M. Sheldon, A.J. Elliot, Not all personal goals are personal: Comparing autonomous and controlled reasons for goals as predictors of effort and attainment. Personal. Soc. Psychol. Bull. 24(October), 546-557 (1998) https://doi.org/10. $1016 / 50140$

Sottilare, R. A. (2014). Fundamentals of adaptive intelligent tutoring systems for self-regulated learning. In Proceedings of the Interservice/Industry Training Simulation and Education Conference. Orlando, Florida: National Training and Simulation Association (NTSA). 
J.G. Tront, Facilitating pedagogical practices through a large-scale tablet PC deployment. Computer 40(9), 62-68 (2007) https://doi.org/10.1109/MC.2007.310

R.J. Vallerand, L.G. Pelletier, M.R. Blais, N.M. Briere, C. Senecal, E.F. Vallieres, The academic motivation scale: A measure of intrinsic, extrinsic, and Amotivation in education. Educ. Psychol. Meas. 52(4), 1003-1017 (1992) https://doi.org/10. $1177 / 0013164492052004025$

Wang, T., \& Towey, D. (2012). A rethinking of digital learning device projects. In Proceedings of IEEE International Conference on Teaching, Assessment, and Learning for Engineering, TALE 2012. https://doi.org/10.1109/TALE.2012. 6360298

Weiner, B. (2008). Reflections on the history of attribution theory and research: People, personalities, publications, problems. Social Psychology. https://doi.org/10.1027/1864-9335.39.3.151

Wigfield, A., \& Eccles, J. S. Expectancy-value theory of achievement motivation. Contemp Educ Psychol 25(1), 68-81 (2000) https://doi.org/10.1006/ceps.1999.1015

A. Wigfield, S. Tonks, S.L. Klauda, in Handbook of Motivation at School. Expectancy-value theory (2009), pp. 55-75

M. Windschitl, K. Sahl, Tracing teachers' use of Technology in a Laptop Computer School: The interplay of teacher beliefs, social dynamics, and institutional culture. Am. Educ. Res. J. 39(1), 165-205 (2002) https://doi.org/10.3102/ 00028312039001165

Wu, F. T., Mou, Z. J., Control, E., Information, S., International Frontiers of Science, and, Research, A., \& Technology Research, A. (2014). A model of personalized analysis on students' learning based on big data. In 2014 International Conference on Computer, Intelligent Computing and Education Technology, CICET 2014 (Vol. 2, pp. 771-774)

Xie, Y., Sun, N., Mei, X., Kong, Z., \& Kwok, L. F. (2016). Research of English Oral Communication Ability Cultivating Model in Junior Middle School Based on E-Schoolbag. In Proceedings - 2015 International Conference of Educational Innovation Through Technology, EITT 2015 (pp. 247-252). https://doi.org/10.1109/EITT.2015.59

Xie, Y., Wang, Q., Li, Y., Kwok, L. F., Yang, Y., \& Guo, F. (2015). Research on problem-oriented instruction mode supported by electronic schoolbag. In Lecture Notes in Computer Science (including subseries Lecture Notes in Artificial Intelligence and Lecture Notes in Bioinformatics) (Vol. 9167, pp. 231-242). https://doi.org/10.1007/978-3-319-20621-9_19

B.J. Zimmerman, Self-efficacy: An essential motive to learn. Contemp. Educ. Psychol. 25, 82-91 (2000) https://doi.org/10 1006/ceps.1999.1016

Submit your manuscript to a SpringerOpen ${ }^{\circ}$ journal and benefit from:

- Convenient online submission

- Rigorous peer review

- Open access: articles freely available online

- High visibility within the field

- Retaining the copyright to your article

Submit your next manuscript at $>$ springeropen.com 